
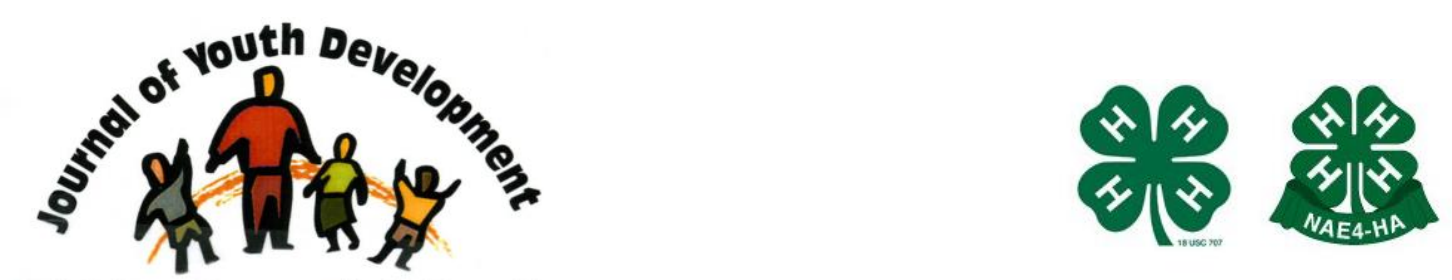

Bridging Research \& Practice

\title{
The Accordion Effect: Is Quality in Afterschool Getting the Squeeze?
}

\author{
Dana Fusco \\ York College \\ City University of New York \\ dfusco@york.cuny.edu \\ Anne Lawrence \\ Robert Bowne Foundation \\ Susan Matloff-Nieves \\ Queens Community House
}

Esteban Ramos

Fresh Youth Initiatives 


\title{
JOURNAL OF YOUTH DEVELOPMENT \\ bridging research and practice

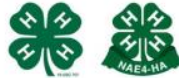

Volume 8, Number 2, Summer 2013

Article 130802FA001

\section{The Accordion Effect: Is Quality in Afterschool Getting the Squeeze?}

\author{
Dana Fusco \\ City University of New York \\ Anne Lawrence \\ Robert Bowne Foundation \\ Susan Matloff-Nieves \\ Queens Community House \\ Esteban Ramos \\ Fresh Youth Initiatives
}

\begin{abstract}
Community-based afterschool programs remain places that support youth development. However, in most places quality is getting the squeeze, making it more difficult to meet the growing needs of youth and parents. This article describes the impact of increased external and regulatory pressures that have taken hold at a time of reduced financial and social capital. In this article, we name the factors that are creating what we call The Accordion Effect and describe its 'squeezing' impact on quality programming. We conclude with recommendations for reclaiming quality youth work, a practice that we believe must remain holistic and emergent.
\end{abstract}

\section{Introduction}

Twenty years ago, community-based afterschool programs were described as beacons of hope (McLaughlin, Irby, \& Langman, 1994), therapeutic milieus (Glover, 1995), 'a different kind of child development institution' (Halpern, 2002), places to imagine the unimaginable (McLaughlin, Irby, \& Langman, 1994), and a place to call home (Hirsch, 2005). They earned these descriptions by creating safe spaces that were responsive to local youth and community context (Charlesworth, 2008; Christens, \& Peterson, 2011; Fusco, 2011; VanderVen, 1999) where young people could build a range of competencies and efficacy (National Research Council and Institute of Medicine, 2002). Today, that practice is being threatened. Relational processes are being stifled by top-down measures of accountability and managerial procedures for ensuring 
'efficiency.' In afterschool programs, the squeeze arises in part from increased pressures to do 'school lite' (Halpern, 2002; Heathfield, 2012). A recent conversation with a program director illustrates this pressure well:

Just yesterday, we found that we could add wonderful music instruction as well as drama for one of our programs. Yet we feel boxed in with how we are forced to rearrange the schedule to ensure that we meet the required hours for STEM \& Literacy. It's bad enough that Arts are cut from the school day, but after school programming should be a place where we have the freedom and creativity to design programs without academic rigor, as our staff are not teachers! Yet we are still forced to make these accommodations in continued attempts to compensate for the failing educational system (J. Tibbets, personal communication, March 5, 2013).

Schooling is "overriding more broadly framed community association and informal education concerns" (Heathfield, 2012, p. 88). This change in purpose and forcing of predetermined outcomes has led to different ways of being with young people during afterschool hours. Processes of youth engagement such as agency and voice are difficult to maintain in authentic ways when goals are predetermined rather than emerging organically from youth and community needs. As Robert Halpern warned, "it will be difficult for school-age programs to create the psychological space children need if there is too much pressure to serve instrumental purposes" (1999, p. 93).

It was from this concern that we wanted to understand how practitioners, particularly those who had been in the field long enough to recognize this shift in purpose and practice, were managing to serve young people and urban communities responsively. Lawrence, a program officer at the Robert Bowne Foundation, has used her role to support the development of quality programs that offer literacy education to children and youth living in diverse neighborhoods throughout New York City. The Bowne Foundation believes out-of-school time (OST) programs should support the literacy development of children and youth by involving them in youth-centered, innovative, exciting and engaging activities, but not more school after school. Fusco, a professor at York College, has been studying the role of youth programs in promoting the development of young people since the 1990's and was increasingly concerned about the 'disappearance' of youth-led responsive spaces during nonschool hours. Together, we wanted to understand how practitioners were coping with the shifts that we were observing. We invited long-time community youth workers, Ramos and Matloff-Nieves, to a series of conversations on the "Past, Present, and Future of Youthwork." In research parlance, one might describe these conversations as focus groups. However, we are not inclined to treat this piece as research or present our thoughts as "data." We were not neutral observers, but affected actors and not ones without strong opinions. In this regard, this article is an attempt to capture the essence of those conversations in order to raise awareness about the times in which youthwork lives (and possibly dies) through the eyes of practitioners. We do that by first comparing past and present practices in youth work.

\section{Past and Present Practices in Youth Work}

In 2011, thirteen community youthwork leaders in New York City were invited to discuss the past, present and future of youthwork. Members of the group had several things in common: they work in some of the most challenged areas of the city; they have dedicated their lives to working with young people; and they are a creative and inspiring group of master practitioners who manage to navigate a sometimes unforgiving system in order to ensure that young people in some of the most toxic environments thrive. 
It was through our conversations with this esteemed group that the contrast between the past and present of youthwork practice became starkly noticeable. The youth work of the past was a relational practice that was supported by more humanistic policies and conditions. Each of the leaders spoke of times when you could expose young people to the vast world around them, broaden their horizons and restore hope. This was done gradually through a variety of experiences that emerged from getting to know the young people. In conversation with young people, their dreams, wishes, questions, concerns, misconceptions, and ideas were released and then built upon. Youth work was not 'about' something predetermined but was an emergent, responsive way of being with young people that dealt with multiple personal and social needs. What was common across the group's memories was the impact that was observed in a wide array of developmental outcomes from this sort of practice, e.g., the tough girl who finally let her shield down to play in the sprinklers, the nine-year old boy who sat through a meeting without punching someone, the teen who was accepted to college, or a young person for whom English is a second language who found her public voice.

Recollecting on past experiences took on greater importance than we initially intended because it reminded us that youth work is not a one-size-fits-all mould for meeting 'targets' but rather is a diverse, plethora of opportunities; a family of practices (Baizerman, 1996) that is potentially transformational and life changing for many young people (Heath \& McLaughlin, 1996; Hirsch, 2005; McLaughlin, Irby \& Langman, 1994). Quality youth work by definition begins with youth driven practice responses; it is "bottom up" rather than "top down." Right now in New York City and around the world (e.g., see U.K. campaign In Defence of Youth Work, 2012), it is difficult for youth workers to engage in relational youth work well. The practitioners in our group unanimously described the present conditions of working in community youth organizations as stressful, overwhelming, and impossible. Such conditions are resulting in what we are calling, "the Accordion Effect," an effect that leaves little room for conversation and no time for reflection (see Figure 1).

Figure 1

The Accordion Effect: Squeezing out Quality

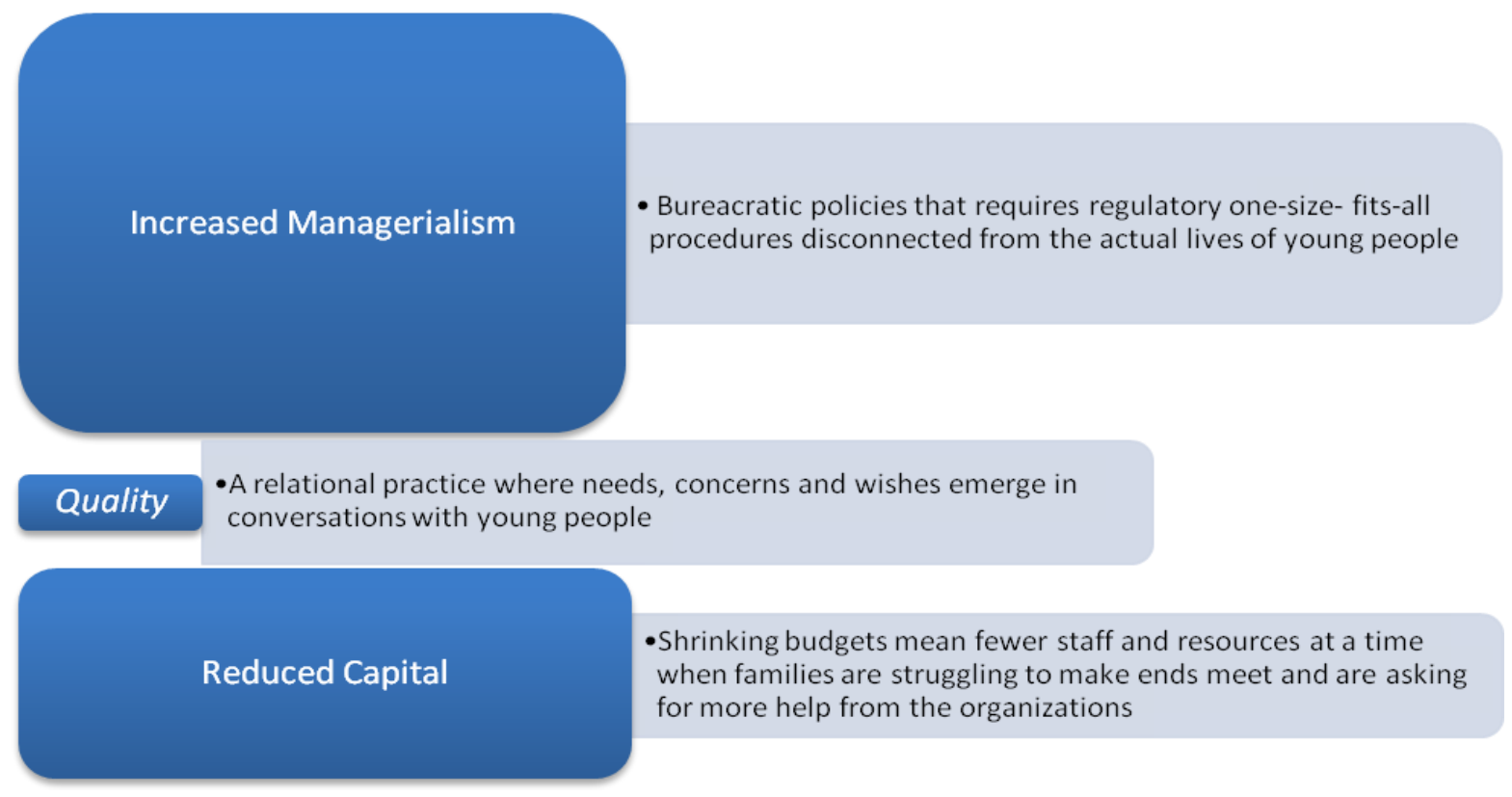


Top-down pressures and growing expectations to do more with less at a time of decreased resources and swelling bottom-up demands are putting the squeeze on organizations like never before witnessed (in our lifetimes). Youthwork practitioners are in the middle caught in stressful attempts to keep up and keep on. They are despairingly and tirelessly working to push up, push back, and hold on.

Next, we present two case examples of the Accordion Effect that illustrate how the current system is contributing to the squeezing out of quality youthwork practice in communities that need responsive practice the most. We then offer five recommendations for creating a system that is better aligned to supporting what we consider quality practices with young people.

\section{Got Jumped! Case example from Fresh Youth Initiatives}

Fresh Youth Initiative (FYI) was launched in 1993 to provide young people in the Washington Heights section of New York City a place to develop their leadership skills, fulfill their potential, and realize their dreams. FYI accomplishes this mission through qualitative guidance, academic support, exposure to new experiences, and community service activities. As a not for profit organization, FYI has to submit proposals to foundations and government agencies for funding. When a proposal is submitted, an understanding between the funding institution and the organization is made with regard to the scope of work that will be provided. Because qualitative guidance is dialogic, it is difficult to articulate the outcomes in advance of the practice.

Therefore, the formalized scope of work written into contracts usually includes only the handson activities that youth participate in, and not the guidance activities. Unfortunately, not many funding institutions understand the importance of having conversations with young people as a valid and effective practice, unless it fits into a "mental health" tick box. FYI does not have psychologists or psychiatrists on staff; rather, they have a team of people who have lived through many of the presenting issues a young person brings to them and are therefore able to provide them with guidance. The paradox is that while this 'guidance' results in the most transformational outcomes, it is difficult to explain to a funding institution that sometimes a presenting social problem should take precedence over homework help, tutoring, or enrichment. The following is a story of how FYI meets the children "where they're at" and takes a presenting problem and turns it into a teachable moment through qualitative guidance.

The story begins with two brothers (Joey and Danny) who were participants at FYI. Joey, the older of the two and considered a "tough kid," would get out of school earlier arriving at FYI before Danny. One day upon arrival, the staff noticed that Danny looked distraught. The person at the sign-in table noticing Danny was upset asked, "What happened?" Danny responded by telling her that he was walking to FYI from school and passed by a large group of kids that were hanging out on a corner. As Danny passed the group of kids, one of the kids made a statement referring to Danny. Danny, not being one to remain quiet at such teasing, responded to the statement that was made. Upon responding to the statement, Danny was pummeled by the whole group. After listening to the story, the staff member told Danny to "relax" and "go get something to eat." As Danny went to get something to eat, the staff member relayed the information to the Program Director. As that communication was occurring among the adults, Danny was telling his story to Joey. Joey was obviously furious and his anger was spilling into the feelings of the other participants to the point that a large number of FYI participants were ready to leave the building to go and confront the large group of kids standing on the corner. At that moment a decision was made by the team to abandon the planned activities and rather engage the young people in a dialogue about 'getting jumped.' To the staff the day was a success $\sim$ a potentially violent situation was adverted and the young 
people reflected on the experience and learned a valuable lesson about how to handle such situations in the future. To the funding agency, it was a day that FYI was "closed" because the scope of work was not delivered. This meant that on this day FYI did not receive its' per child compensation for the day.

This is a clear example of the Accordion Effect: the squeezing pressure arising from responding to the holistic and emergent needs of young people while meeting accountability demands of the funding institution, whose own needs are sometimes misaligned to the practice of youth work. In that moment, staff used their professional judgment to decide that most important was ensuring that the young people were educated about the issue and that they weren't going to retaliate and put themselves in jeopardy. A dilemma became a teachable moment. There have been many instances where situations like this occur and programs recalibrate based on the needs of the youth. Not only do we need to understand this concept and follow through with the young person, but if an adolescent has a particular developmental need, chances are that others in the same age group will either have gone through or will be going through a similar situation.

\section{Case Example: Queens Community House}

Queens Community House is a community-based, multiservice agency in New York City that has operated programs for children and youth since 1975. Some of these programs include partnerships with schools that were initiated as early as 1983. During a summer planning meeting, one principal commented that he could not imagine running the school without the $\mathrm{QCH}$ after school program. Another principal valued the work of the program director, a very seasoned social worker, with children with mental health and social-emotional issues and their families. In that program, approximately $30 \%$ of the children have experienced past trauma, have learning disabilities and adjustment issues related to a history of immigration, and/or present family and mental health issues. These principals and school staff value the opportunities for social, recreational and physical activities for buffering complex needs of children, families and communities.

In spite of the clear value that school partners place on the social and emotional benefits of after school, the outcomes in most contracts are at variance with these goals. The $21^{\text {st }}$ Century Learning Centers funding requires reporting on grades and standardized test scores. At one of QCH's middle school sites, the program director noted that while participants improved by several points in their math scores, the reading scores remained fairly level. In looking at the comparative ELA scores, it was noted that this is a school with a very large number of recent immigrants, many who would have been exempt from the ELA examinations in past years. As the federal requirements have moved up the timeframe for testing new arrivals to the U.S., the scores in those schools have gone down. In all honesty, can QCH claim credit for the gains when all students attending that school showed the same achievement? Similarly, does QCH take the blame when scores go down or stay the same?

Similarly, a public funding source of many of the program sites has a stringent attendance policy. If the overall program does not maintain a certain level of attendance, $20 \%$ of the program expenditures are denied reimbursement at the end of the year. As a result, the director has to turn away children whose families cannot commit to five days of weekly attendance because the children may have therapeutic or tutoring appointments that conflict with daily program attendance. Because QCH is also constrained by a separate system that licenses the sites to ensure that there is always a 1:10 staff to child ratio, they cannot 
accommodate "one extra child" for a few days a week. These two constraints prevent the organization from serving some of the highest need children.

As if these regulations that are misaligned to the everyday realities of programs are not strain enough, shrinking budgets impact the ability of programs to respond to complex needs. One of the middle school sites is heavily afflicted by gang activity. The sense of belonging and safety of the afterschool program provides, as well as an ability to allow youth to attend sporadically until they were fully engaged, were essential. The program for many years enjoyed an unusually high level of staff retention, averaging $80 \%$ of staff returning from year to year. The funding level is now half what it was ten years ago, and the director struggles to maintain full staffing, often having to fill in for absent staff himself. At the same time, his continuous presence and ability to engage youth creates a safe space that keeps young people connected even after they graduate. He is able to respond to the interests of youth and offers ample opportunities for them to select and shape activities. It is not uncommon to see youth choosing what game to play on a given day and then negotiating the rules, thus developing skills in group decisionmaking, conflict resolution and communication. Observers with deep experience in youth development, including the school principal, appreciate these opportunities for participants to work on important life skills, particularly in a neighborhood where their peers are making dangerous choices and resolving conflicts by violence. However, to a site monitor looking for conformity of curriculum, planned lessons and academic outcomes, these interactions appear to be evidence of poor activity planning. QCH, which has served thousands of young people over the years, is struggling to maintain an approach that they have learned works.

\section{Recommendations}

As our two case examples exemplify, managerial and epistemic models are out of alignment with, and creating barriers, to relational practice. In the name of accountability, youth work is diminished to results that are easily measurable, but not necessarily most important. Children and youth are seen as widgets that can be fixed more efficiently if the right algorithm is applied. Therefore, "we are pressed to do the truly complex and responsive work around the edges and in spite of narrow restrictions" (personal communication, Irma Rodriguez, Executive Director of Queens Community House, February 6, 2013). This squeeze and squeezing out of quality is not specific to New York City but is the experience of those throughout the nation and indeed the world. At a recent national conference, we found very strong agreement on the universality of the Accordion Effect among audience members who were from cities and towns around the country (Ramos, Lawrence, \& Fusco, 2012). Recent efforts in the U.K. such as, the In Defence of Youth Work Campaign, suggest similar struggles. Youth work professionals are voicing their concerns passionately that it is time to turn the tide.

Like all squeezeboxes, accordions require expansion to work effectively. Expansion requires responsiveness, not standardization. One of the focus group participants aptly noted,

I think as we define what we do its really important to define it in terms of that human connection and the fact that within that there will not be standardization and there needs to be a place in these kids life where they are not eating standardized food and not having a standardized experience with others.

Here we offer a set of suggestions for providing expansion into an overly squeezed system of accountability that asks for 'evidence' based on reductionist rather than relational principles (Fusco, 2013). That expansion, we believe, rests on the following essential principle: Youth 
work is a relational practice that is both holistic and emergent. Thus, we recommend conversations that help us move forward on the following FAITH:

- $\quad$ Flexibility for programs to respond to the emerging goals, aspirations and concerns of participating youth and their families and to the conditions affecting the risks and opportunities for youth in their target communities. This requires an understanding that youthwork practices engage multiple developmental and social domains. "I got jumped" is one of an endless number of stories that exemplifies that youth work requires the flexibility to respond to "teachable moments" that emerge in the everyday grit of programs. Such a recommendation has been supported by those in allied relational professions such as social work (Cooper, 2011; Freedberg, 2009), healthcare (Titchen \& Ersser, 2001) and education (Van Manen, 1991).

- $\quad$ Accountability that understands that human growth is not linear, takes time to 'appear,' and is not reducible to human bits. Accountability systems that are aligned to the practice of youth work would not negate or de-legitimatize days with young people such as the two exemplified in our case examples but would account for "teachable moments" as a critical component of the power of the work, without which young people lose valuable opportunities to grow. Predetermined outcomes might be realistic for some situations but when young people express issues that are "outside of" the tick box, youth workers will respond; it is only because they do, that the most powerful, transformational life outcomes result.

- Inclusivity as a necessary methodology for beginning the work. The building of practice responses emerges dialogically with youth participants. It is situated in the ecological, sociological and ontological, in the daily 'being with' young people; thus, practice cannot be driven by universal principles of development, national priorities, or a funder's unique mission. Programs and policies must emerge from an inclusive and authentic set of voices and perspectives, beginning with the priorities of young people, their families and their communities.

- $\quad$ Trust and explicit respect for youth workers whose professional judgments are made in response to the day-to-day needs of young people. This requires an understanding that youth workers' judgments are not just about what is good or best to do but what is right to do. Presenting conditions within the daily grit of running programs are the basis of professional decisions. These decisions will sometimes appear at odds with contractual targets for the day but more often are within assurances of quality, that is, for meeting young people where they are at, with whatever presenting problems as well as goals, wishes, and dreams that the youth bring to the program.

- $\quad$ Humanistic budgets that treat workers with dignity. Dollars (minimally $10 \%$ of budgets) should be earmarked for General Support (GS). Programs need a GS fund in order pay a minimum wage to hourly workers to attend staff trainings and meetings, to stay late when a parent is late picking up their child from the program, etc. A related issue is adequate funding to pay staff a living wage and Cost of Living Adjustments (COLA's) in contracts so deserving staff can receive pay raises.

FAITH is required if youthwork is to be reclaimed as a holistic and emergent relational practice, a practice shown to be effective and impactful for young people for close to one hundred years (See the special edition of Journal of Youth Development, Fall 2012: 100 years of research on youth development). Two of the recommendations we make operate at a macro-level, through choices made at a legislative and policy level: Accountability that fits and Humanistic Budgeting 
(see Figure 2). The remaining FIT (Flexibility, Inclusivity, and Trust) are micro-processes will not work without addressing the systemic policies and procedures that continue to work against it.

\section{Figure 2}

System factors to support youthwork as a relational practice

\section{Relational Practice is}

\section{Holistic \&}

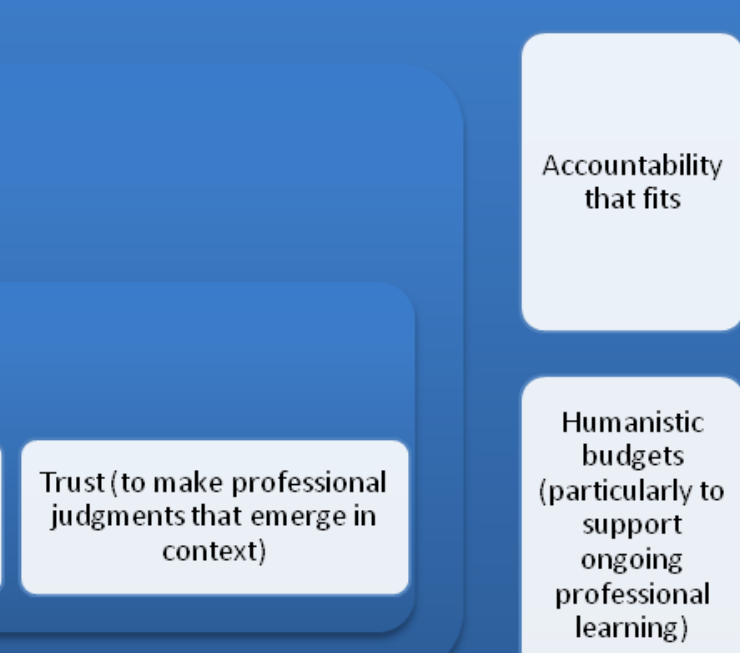

Thus, advocacy of FAITH is a critical next step if youth work is to be reclaimed. Our voice in the policy arena is a necessary conduit for widening the current thinking, dialogue and policy decisions. The Bowne Foundation is exploring one model of advocacy. Bowne is funding advocacy on a city, state and national level and is proposing to create a full-time position to advocate for community-based youth programs. Bowne has collaborated with other youth funders to hire a professional media and messaging expert to work with advocacy organizations on messaging as a critical component of the overall strategy they need for success. What will be the message, who will construct it, who will be the audience(s), and towards what end? These are critical questions that will need to be formulated, and some, answered if youth work is to maintain a vital and necessary role in the lives of young people and communities.

Acknowledgement: We would like to thank Jeanne Tibbets from BronxWorks and Steven Portericker from Union Settlement Association for their contributions to this work, as well as the additional participants of our focus group conversations who do amazing work despite an unforgiving system. 


\section{References}

Baizerman, M. (1996). Youth work on the street. Community's moral compact with its young people. Childhood, 3, 157-165.

Charlesworth, J. (2008). Inquiry into issues of voice in relational practice. In G. Bellefeuille and F. Ricks (Eds.), Standing on the precipice: inquiry into the creative potential of child and youth care practice (pp. 231-280). Edmonton, Alberta: MacEwan Press.

Christens, B.D., \& Peterson, N.A. (2011). The role of empowerment in youth development: A study of sociopolitical control as mediator of ecological systems' influence on developmental outcomes. Journal of Youth and Adolescence, 41, 623-635.

Cooper, B. (2011). Criticality and reflexivity: best practice in uncertain environments. In J. Seden, S. Matthews, M. McCormick, \& A. Morgan (Eds.), Professional development in social work: Complex issues in practice (pp. 17-23). New York: Routledge.

Freedberg, S. (2009). Relational theory for social work practice: A feminist perspective. New York: Routledge.

Fusco, D. (2011). Framing trends, posing questions. In D. Fusco (Ed.), Advancing Youth Work: Current trends, Critical Questions (pp. 216-231). New York, NY: Routledge.

Fusco, D. (2013). Is youth work being courted by the appropriate suitor? Child \& Youth Services, 34, 196-209.

Glover, J. (1995). Promoting youth development in a therapeutic milieu. Contract with America's youth: Toward a national youth development agenda (pp. 22-23). Washington, DC: American Youth Policy Forum.

Halpern, R. (1999). After-school programs for low-income children: Promises and challenges. The Future of Children, 9, 81-95. Los Altos, CA: The David and Lucille Packard Foundation.

Halpern, R. (2002). A different kind of child development institution: The history of after-school programs for low-income children. Teacher's College Record, 104, 178-211. New York: Teacher's College, Columbia University.

Heath, S.B., \& McLaughlin, M.W. (1996). The best of both worlds: Connecting schools and community youth organizations for all-day, all-year learning. In J.G. Cibulka \& W.J. Kritek (Eds.), Coordination among schools, families, and communications (pp. 69-94). Albany, New York: SUNY Press.

Heathfield, M. (2012). A Chicago story: Challenge and change. In D. Fusco (Ed.), Advancing youth work: Current trends, critical questions (pp. 85-99). New York, NY: Routledge.

Hirsch, B.J. (2005). A place to call home: After-school programs for urban youth. New York: Teachers College Press.

In Defence of Youth Work. (2012). This is youth work: Stories from practice. UK: In Defence of Youth Work. 
McLaughlin, M.W., Irby, M.A., \& Langman, J. (1994). Urban Sanctuaries: Neighborhood organizations in the lives and futures of inner-city youth. San Francisco: Jossey-Bass.

National Research Council and Institute of Medicine. (2002). Community youth programs to promote positive youth development. Washington, DC: National Research Council and Institute of Medicine.

Ramos, E., Lawrence, A., \& Fusco, D. (2012). The Accordion Effect: The squeeze between external pressures, increased expectations and reduced funding. Paper presented at the annual meeting of the National Afterschool Association. April, Dallas, TX.

Titchen, A., \& Ersser, S.J. (2001). Explicating, creating and validating professional craft knowledge. In J. Higgs \& A. Titchen. (Eds.), Practice knowledge \& expertise in the health professions (pp. 48-56). Oxford: Butterworth-Heinemann.

Van Manen, M. (1991). The tact of teaching: The meaning of pedagogical thoughtfulness. New York: State University of New York Press.

VanderVen, K. (1999). You are what you do and become what you've done: The role of activity in development of self: A non-linear dynamic systems relational approach. Journal of Child and Youth Care, 13, 133-147.

(C) Copyright of Journal of Youth Development Bridging Research and Practice. Content may not be copied or emailed to multiple sites or posted to a listserv without copyright holder's express written permission. Contact Editor at: patricia.dawson@oregonstate.edu for details. However, users may print, download or email articles for individual use.

ISSN 2325-4009 (Print); ISSN 2325-4017 (Online) 